\title{
A Classification of Controlled Interpersonal Affect Regulation Strategies
}

\author{
Karen Niven, Peter Totterdell, and David Holman \\ University of Sheffield
}

\begin{abstract}
Controlled interpersonal affect regulation refers to the deliberate regulation of someone else's affect. Building on existing research concerning this everyday process, the authors describe the development of a theoretical classification scheme that distinguishes between the types of strategy used to achieve interpersonal affect regulation. To test the theoretical classification, the authors generated a corpus of 378 distinct strategies using self-report questionnaires and diaries completed by student and working samples. Twenty participants then performed a card-sort of the strategies. Hierarchical cluster analysis was used to determine how well the theoretical classification represented spontaneous understandings of controlled interpersonal affect regulation. The final classification primarily distinguished between strategies used to improve versus those used to worsen others' affect, and between strategies that engaged the target in a situation or affective state versus relationship-oriented strategies. The classification provides a meaningful basis for organizing existing research and making future conceptual and empirical distinctions.
\end{abstract}

Keywords: affect regulation, classification, influence, mood, emotion management

Deliberate attempts to regulate the feelings of others are a notable feature of social life. Most people can probably recall a time when they have tried to make someone feel guilty for neglecting them, or a time when they have tried to cheer someone up who was feeling miserable. Indeed research shows that the process of deliberately influencing the feeling states of another personcontrolled interpersonal affect regulation-occurs between a variety of interlocutors and in a variety of contexts (e.g., Francis, Monahan, \& Berger, 1999; Thoits, 1996; Thompson \& Meyer, 2007). Although controlled interpersonal affect regulation has been described in many different domains, literature concerning the strategies used to achieve this process has yet to be integrated. The lack of common framework in this area is likely to inhibit the interpretability of previous and future research on this social phenomenon. The aim of this research was therefore to develop a classification of controlled interpersonal affect regulation strategies.

\section{Interpersonal Affect Regulation}

Research on affect has shifted away from a solely intraindividual perspective, toward one which embraces a social perspective (e.g., Parkinson, Fischer, \& Manstead, 2005). This shift has been coupled with a corresponding trend with respect to affect regulation.

Affect regulation is "the process of initiating, maintaining, modulating, or changing the occurrence, intensity, or duration of internal feeling states" (Eisenberg, Fabes, Guthrie, \& Reiser, 2000, p. 137), and can occur at two different levels of processing (cf.

Karen Niven, Peter Totterdell, and David Holman, Institute of Work Psychology, University of Sheffield, Sheffield, England.

The support of the Economic and Social Research Council (ESRC) United Kingdom is gratefully acknowledged. We would also like to thank Sarah Drabble and Uta Bindl for their help with coding.

Correspondence concerning this article should be addressed to Karen Niven, Institute of Work Psychology, University of Sheffield, Sheffield S10 2TN, England. E-mail: k.niven@ sheffield.ac.uk
Shiffrin \& Schneider, 1977): an automatic level, occurring without conscious awareness; and a controlled level, involving the deliberate use of strategies that require conscious intent, awareness, and monitoring. Although some have used the term affect regulation very broadly, to include coping and psychological defenses (e.g., Gross \& Thompson, 2007), we use the term more specifically to refer to the regulation of emotions and mood states. The process of affect regulation has traditionally been examined from an intraindividual perspective, with researchers investigating the ways in which people influence their own emotions and moods (e.g., Gross, 1998). In recent years, interpersonal affect regulation-the process of influencing the internal feeling state(s) of another person-has been increasingly and more widely recognized as an important form of affect regulation, although there has been interest in extrinsic affect regulation processes among developmental researchers for some time (e.g., Gianino \& Tronick, 1988).

A great deal of research concerning interpersonal affect regulation has focused on the automatic level of processing, in which affect spreads from one person to another without conscious awareness (e.g., Totterdell, Kellett, Teuchmann, \& Briner, 1998). Nonetheless, interpersonal regulation of affect also occurs at a conscious level of processing, often as a result of deliberate attempts that involve intent and awareness on the part of the person performing the regulation. Such deliberate attempts are referred to as controlled interpersonal affect regulation. It should be noted that controlled and automatic interpersonal affect regulation are not necessarily completely distinct categories of regulation, because behaviors that change others' feelings (e.g., physical acts of comforting) could initially be used deliberately but over time be used habitually, without conscious awareness (Gross, 1998, 1999).

\section{Previous Research on Controlled Interpersonal Affect Regulation}

Controlled interpersonal affect regulation has been studied across a wide range of research domains (see Table 1, column 1). 
Table 1

Strategies Used To Achieve Controlled Interpersonal Affect Regulation Identified From Existing Literature

\begin{tabular}{|c|c|}
\hline Area of literature & Strategy of achieving controlled interpersonal affect regulation \\
\hline $\begin{array}{l}\text { Interpersonal affect regulation and interpersonal } \\
\text { emotion management }\end{array}$ & $\begin{array}{l}\text { Cahill and Eggleston (1994): Humor, laughing at oneself, masking one's own emotions, sarcasm, } \\
\text { hostility, gratitude } \\
\text { Crawley (2004): Black humor, hiding one's own emotions } \\
\text { Field (1994): Reciprocating and reinforcing reactions } \\
\text { Francis et al. (1999): Humor } \\
\text { Gross and Thompson (2007): Selecting situations for others } \\
\text { Lively (2000): Practical help, agreeing, listening, letting the person vent, mere presence, empathy, } \\
\text { the telling of "horror stories," the use of humor at the expense of superiors, the acting out of } \\
\text { emotional or stressful events, taking an interest } \\
\text { Locke (1996): Humor } \\
\text { Pierce (1999): Smiling, presenting positive cheer, listening to anxieties, offer reassurance, flirting, } \\
\text { complimenting } \\
\text { Schrock et al. (2004): Humor, supportive interchanges, affirmations of each other's identity, } \\
\text { sharing stories } \\
\text { Thoits (1996): Group enactments of problems or concerns, acts of support or comforting } \\
\text { Thompson and Meyer (2007): Physical soothing, mirroring or ignoring affective responses, } \\
\text { distracting attention } \\
\text { Vangelisti et al. (1991): Reminding of obligations, listing sacrifices, reminding the person of his } \\
\text { or her role responsibilities, making comparisons to others }\end{array}$ \\
\hline Emotional labor & $\begin{array}{l}\text { Rafaeli and Sutton (1990): Displaying positive emotions } \\
\text { Sutton (1991): Altering one's own emotional display, humor }\end{array}$ \\
\hline Interpersonal influence & $\begin{array}{l}\text { Buss (1992): Twelve types of interpersonal influence used in close relationships: charm, reason, } \\
\text { coercion, silent treatment, responsibility invocation, monetary reward, pleasure induction, social } \\
\text { comparison, reciprocity, debasement, regression, and hardball } \\
\text { Goffman (1955): Impression management } \\
\text { Jones and Pittman (1982): Self-promotion } \\
\text { Kipnis, Schmidt and Wilkinson (1980): Eight types of interpersonal influence used to get ahead at } \\
\text { work: assertiveness, rationality, sanctions, ingratiation, exchange, upward appeal, coalitions, and } \\
\text { blocking } \\
\text { Rafaeli and Sutton (1991): Emotional contrast }\end{array}$ \\
\hline Social support & $\begin{array}{l}\text { Henderson and Argyle (1985): Helping the person, discussing work, chatting casually, teaching } \\
\text { the person, joking, teasing, discussing your personal life, discussing your feelings, asking or } \\
\text { giving personal advice, having food together } \\
\text { House and Kahn (1985): Three types of social support: instrumental (practical or tangible help, } \\
\text { providing material goods), informational (providing guidance and advice), emotional } \\
\text { (communicating caring and concern, showing love, sympathy and understanding, valuing, } \\
\text { "being there," listening, empathizing, reassuring, comforting) }\end{array}$ \\
\hline Caregiving & $\begin{array}{l}\text { Kahn (1993): Eight behavioral dimensions of caregiving: accessibility (presence, talking, } \\
\text { listening), inquiry (asking how the person feels, withholding judgment), attention (eye contact, } \\
\text { nodding), validation (communicating positive regard and appreciation), empathy, support } \\
\text { (reframing and analyzing situations, providing resources), compassion (warmth, affection, } \\
\text { kindness, smiling, joking), consistency }\end{array}$ \\
\hline Toxin handling & $\begin{array}{l}\text { Frost and Robinson (1999): Open listening, eye contact, attention, allowing person to vent, giving } \\
\text { practical support, reappraising negative situations }\end{array}$ \\
\hline Energizing & $\begin{array}{l}\text { Cross et al. (2003): Smiling, speaking with enthusiastic tones, inviting others' contributions, } \\
\text { valuing others' opinions, active listening }\end{array}$ \\
\hline Bullying & $\begin{array}{l}\text { Neuman and Baron (1998): Negative eye contact, belittling, silent treatment, mockery, flaunting } \\
\text { status, aggression, shouting, swearing, ostracism }\end{array}$ \\
\hline
\end{tabular}

Studies that focus primarily on controlled interpersonal affect regulation typically examine the regulation of other people's $e x$ perienced affect, although people may also try to influence the way that others express their emotions or moods (e.g., parents teaching their children to look happy when they receive gifts). ${ }^{1}$ Deliberate attempts to regulate others' experienced affect have been reported between family members and partners (Vangelisti, Daly, \& Rudnick, 1991), parents and children (Field, 1994; Thompson \& Meyer, 2007), support group members (Schrock, Holden, \& Reid, 2004; Thoits, 1996), relative strangers (Cahill \& Eggleston, 1994), and employees and their coworkers, managers, customers, or clients in various work domains (e.g., in hospitals, Francis et al.,
1999; Locke, 1996; legal firms, Lively, 2000; Pierce, 1999, and prisons; Crawley, 2004)

Controlled interpersonal affect regulation has also been studied as part of broader social processes, such as interpersonal influence, in which others' feelings are regulated to influence their attitudes

\footnotetext{
${ }^{1}$ The terms interpersonal affect regulation and interpersonal emotion management are sometimes used interchangeably. However, interpersonal emotion management can be viewed as a broader process that uses a range of behaviors, including interpersonal affect regulation, in a strategic manner to accomplish goals within a relationship.
} 
and behaviors (e.g., Rafaeli \& Sutton, 1991). Likewise, the use of controlled interpersonal affect regulation to improve others' affect has been conceptualized as an element within social support (e.g., House \& Kahn, 1985), caregiving (e.g., Kahn, 1993), and "toxin handling" (helping others deal with difficult emotional situations, e.g., Frost \& Robinson, 1999). Researchers have also positioned the deliberate regulation of others' affect as a form of emotional labor when performed as part of people's job requirements (e.g., Sutton, 1991). Other related areas of research include "energizing" (spreading energy to others in one's social network, e.g., Cross, Baker, \& Parker, 2003) and bullying. Controlled interpersonal affect regulation is conceptually distinct from the processes detailed above, because it is primarily concerned with influencing affect. But it is likely that controlled interpersonal affect regulation is often performed in pursuit of broader social goals, such as influencing someone's attitudes or behavior and strengthening or weakening social relationships.

Despite numerous studies of controlled interpersonal affect regulation, to date there has been no attempt to provide a comprehensive and systematic classification of the strategies used to deliberately regulate others' affect. Until qualitatively different types of controlled interpersonal affect regulation are identified and distinguished, existing studies of interpersonal affect regulation and like processes cannot be compared because it is not clear whether they involve analogous strategies. The ability to answer pertinent questions about interpersonal affect regulation in future research may also be inhibited. For instance, without a meaningful basis upon which to compare strategies, it may be difficult to ascertain which types of interpersonal affect regulation are most effective for changing others' affect.

In this article, we propose and test a generalized conceptual classification of controlled interpersonal affect regulation strategies, which can then be applied selectively to specific contexts and specific transformations of emotions and mood states. In line with the literature in this area, we focus on strategies that are used to regulate other people's experienced as opposed to expressed affect.

\section{Theoretical Classification of Interpersonal Affect Regulation Strategies}

Theories of self-regulation, intrapersonal affect regulation, and interpersonal influence indicate that controlled regulation strategies can be characterized by a motive and the means with which to achieve that motive (Buss, Gomes, Higgins, \& Lauterbach, 1987; Scheier \& Carver, 1988; Totterdell \& Holman, 2003). We therefore sought to capture differences in motives and means in our proposed theoretical framework.

Clearly, a necessary motive in the use of interpersonal affect regulation strategy is to alter another person's affect. Although controlled interpersonal affect regulation is often used to fulfill broader social goals, including strengthening or weakening social relationships, these other motives may only apply in certain contexts. Accordingly, in this article we concentrate on the local motives for performing interpersonal affect regulation. Given the commonly held theoretical distinction between pleasant and unpleasant affect (e.g., Watson \& Tellegen, 1985), we expected that a central distinction in this motive would be between strategies aimed at improving and worsening another's affect. An analogous distinction is also present in numerous theories of intrapersonal affect regulation (e.g., Parrott, 1993; Westen, 1994).

A review of extant literature concerning controlled interpersonal affect regulation and a variety of related interpersonal processes revealed a large number of strategies for regulating others' experienced affect (listed in Table 1). It is likely that there are underlying commonalities and distinctions between these strategies that represent higher-level means of achieving interpersonal affect regulation. However, no one theory from any of these research areas explicitly connects all of these strategies or provides a way of distinguishing between them.

We therefore turned to theories of intrapersonal affect regulation to provide a framework for understanding means of achieving interpersonal affect regulation. For two reasons we focused on Parkinson and Totterdell's (1999) classification of strategies to deliberately improve one's affect. First, this classification provides conceptually rooted distinctions between strategies. Other classifications of intrapersonal affect regulation strategies (e.g., Thayer, Newman, \& McClain, 1994) have been based on the frequency with which strategies are used, as opposed to theory. Second, Parkinson and Totterdell's (1999) classification concerns the regulation of affect (in our terms, emotions and moods), whereas other relevant models have focused on selected components of affect. Gross's (1998) model, for example, focuses on the regulation of emotions, with regulation types including selection and modification of situations that could give rise to emotions. Such categories may not be as appropriate when considering the regulation of mood states, which, unlike emotions, do not always occur in response to particular events (Parkinson, Totterdell, Briner, \& Reynolds, 1996).

Parkinson and Totterdell's (1999) classification has two main distinctions between strategy types. The first distinction is between strategies implemented cognitively and behaviorally. The second distinction is between strategies used to engage oneself in a situation or affective state and those used to divert action or attention away from one's current concern. Although Parkinson and Totterdell (1999) proposed these distinctions only in relation to affect improvement, we predicted that the same distinctions would apply to affect worsening. As such, our theoretical framework (shown in Table 2) differentiated interpersonal affect regulation strategies along three factors, presented here in hierarchical order:

1. Affect improving versus affect worsening. Here a distinction was made between strategies used to initiate, enhance or maintain positive and negative affect in the intended target.

2. Cognitive versus behavioral. Here a distinction was made between strategies that involved the agent attempting to change the target's thoughts or attention in order to exert a change in his or her affect, and strategies that involved the agent using his or her own behavior to exert a change in the target's affect, with no direct attempt to change the target's cognitions.

3. Engagement versus diversion. Here a distinction was made between strategies used to engage the target in his 
Table 2

Theoretical Classification of Controlled Interpersonal Affect Regulation Strategies

\begin{tabular}{|c|c|c|}
\hline Variable & Strategies to improve affect & Strategies to worsen affect \\
\hline \multicolumn{3}{|l|}{ Cognitive } \\
\hline Engagement in situation or affect & $\begin{array}{l}\text { Improving the target's affect by changing the target's } \\
\text { thoughts about his or her situation or affect, e.g., } \\
\text { reframing or reappraisal (discussed in caregiving } \\
\text { and toxin-handling literature: Frost \& Robinson, } \\
\text { 1999; Kahn, 1993) }\end{array}$ & $\begin{array}{l}\text { Worsening the target's affect by changing the target's } \\
\text { thoughts about his or her situation or affect, e.g., } \\
\text { responsibility invocation (discussed in controlled } \\
\text { interpersonal affect regulation and interpersonal } \\
\text { literature: Buss, 1992; Vangelisti et al., 1991) }\end{array}$ \\
\hline $\begin{array}{l}\text { Diversion away from situation or } \\
\text { affect }\end{array}$ & $\begin{array}{l}\text { Improving the target's affect by diverting the target's } \\
\text { attention away from his or her situation or affect, } \\
\text { e.g., use of humor or joking (discussed in controlled } \\
\text { interpersonal affect regulation literature: Cahill \& } \\
\text { Eggleston, 1994; Crawley, 2004; Francis et al., } \\
\text { 1999; Lively, 2000; Schrock et al., 2004) }\end{array}$ & $\begin{array}{l}\text { Worsening the target's affect by diverting the target's } \\
\text { attention away from his or her situation or affect, } \\
\text { e.g., belittling or mocking (discussed in bullying } \\
\text { literature: Neuman \& Baron, 1998) }\end{array}$ \\
\hline \multicolumn{3}{|l|}{ Behavioral } \\
\hline Engagement in situation or affect & $\begin{array}{l}\text { Improving the target's affect by using own behavior to } \\
\text { change the target's situation or affect (no direct } \\
\text { attempt to change the target's thoughts), e.g., giving } \\
\text { practical help (discussed in social support and toxin- } \\
\text { handling literature: Frost \& Robinson, 1999; } \\
\text { Henderson \& Argyle, 1985; House \& Kahn, 1985) }\end{array}$ & $\begin{array}{l}\text { Worsening the target's affect by using own behavior to } \\
\text { change the target's situation or affect (no direct } \\
\text { attempt to change the target's thoughts), e.g., } \\
\text { sanctions or blocking (discussed in interpersonal } \\
\text { influence literature: Kipnis et al., 1980) }\end{array}$ \\
\hline $\begin{array}{l}\text { Diversion away from situation or } \\
\text { affect }\end{array}$ & $\begin{array}{l}\text { Improving the target's affect by using own behavior to } \\
\text { divert the target from his or her situation or affect } \\
\text { (no direct attempt to divert the target's attention), } \\
\text { e.g., displaying positive affect (discussed in } \\
\text { controlled interpersonal affect regulation and } \\
\text { emotional labor literature: Cahill \& Eggleston, } \\
\text { 1994; Crawley, 2004; Pierce, 1999; Rafaeli \& } \\
\text { Sutton, 1990; Sutton, 1991) }\end{array}$ & $\begin{array}{l}\text { Worsening the target's affect by using own behavior to } \\
\text { divert the target from his or her situation or affect } \\
\text { (no direct attempt to divert the target's attention), } \\
\text { e.g., silent treatment (discussed in interpersonal } \\
\text { influence and bullying literature: Buss, 1992; } \\
\text { Neuman \& Baron, 1998) }\end{array}$ \\
\hline
\end{tabular}

or her affective state or situation and those used to divert the target away from his or her affect or current situation.

These three factors produced eight categories of controlled interpersonal affect regulation. Examples of interpersonal affect regulation strategies identified in existing literature that fit into each of the eight categories are illustrated in Table 2.

By consolidating previous research, the proposed classification provided a starting point from which to examine controlled interpersonal affect regulation strategies and the ways that they relate to each other. To test the classification, the current research sought to determine whether the theoretically based distinctions matched ordinary people's understanding of interpersonal affect regulation strategies. Following the arguments of Shaver, Schwartz, Kirson, and O'Connor (1987), repeated experience with events (in this case, interpersonal affect regulation strategies) leads people to construct mental representations-or schemas-in which categories are formed from common features of the events. People use category systems to understand and guide their social interaction and, as such, these systems reflect the "distinct features of reality that are most important for transactions with the world" (Shaver et al., 1987, p. 1062). Accessing people's category system for interpersonal affect regulation therefore offers a potentially useful and valid way of organizing our understanding of the domain. In contrast, a framework derived from theory is guided more by what is known about the organization of related psychological systems, and therefore offers a different insight. Reconciling the results from each approach should lead to a framework that is grounded in both psychological understanding and everyday behavior, producing distinctions between strategies that have both face and ecological validity.

\section{Method}

Our methodology had three stages. The aim of the first stage was to generate a comprehensive list of strategies that people use to regulate others' affect. The aim of the second stage was for participants to group the strategies generated according to judgments of similarities and differences. The aim of the third stage was to analyze whether our theoretical classification was supported by the classification systems produced by participants in this task.

\section{Stage I: Generating the Interpersonal Affect Regulation Strategies}

To generate an inclusive collection of strategies, we conducted three qualitative studies, all involving self-reports of interpersonal affect regulation attempts. We asked people not only about the behaviors they used toward others, but also about acts performed toward them or that they had witnessed, to avoid missing strategies that may be used habitually. To counter potential difficulties with labeling strategies, we asked participants to describe the behaviors used in their own terms.

The first study focused on strategies that change the valence of others' affect. This study involved a questionnaire completed by 72 undergraduate students ( 12 men and 60 women), aged between 18 and 33 years old $(M=21$ years, $S D=2.6)$. In the questionnaire, participants were asked to give open-ended responses to the questions: "What is the most recent thing you have done to try to (improve/worsen) someone else's mood?" "What do you do most often when trying to (improve/worsen) someone else's mood?" and "What do you believe to be the most effective way to (im- 
prove/worsen) someone else's mood?" Asking about the most commonly used and effective strategies ensured that no obvious strategies were omitted from the final list.

The second study focused on strategies that regulate specific emotion and mood states, and that could be used to change not only the valence but also the intensity of these states. This study used a different questionnaire completed by an opportunity sample of participants. The sample was obtained by distributing copies of the questionnaire in various locations (e.g., cafés and shops) around a major city in the United Kingdom. This recruitment approach was used to elicit a sample that varied greatly in terms of age and background, to generate strategies that would be used in many different types of situations and relationships. Forty-seven people returned this questionnaire (20 men and 27 women), aged between 16 and 68 years old $(M=35$ years, $S D=38.9)$. Among the respondents were lawyers, retail advisors, customer service representatives, and retired and unemployed individuals. The questionnaires comprised four open-ended items, each of which required participants to detail something they or someone they knew had done to regulate someone else's affect. Participants were all given a unique combination of items, which differed according to the affective state participants were asked about, and whether participants were asked about the amplification or suppression of this state. For example, one item was: "Please suggest something that you (or someone you know) have done to make someone else feel more jealous." The affective states used were drawn from a pool, which included both primary and secondary emotions, and moods from the circumplex model of affect (e.g., Watson \& Tellegen, 1985). There were five positive (calmness, happiness, joy, hope, and pride) and five negative (misery, anxiety, anger, guilt, and jealousy) affective states.

The third study focused on contextualized and ecologically valid reports of spontaneous interpersonal affect regulation attempts, and involved a qualitative diary (e.g., Waddington, 2005). Our participants were recruited using a series of adverts placed around different areas of a major city in the United Kingdom. Ten participants (three men and seven women), aged between 23 and 53 years old $(M=34$ years, $S D=12.6)$, completed diaries over a week-long period. At the end of each day during this period, participants were asked: "Please reflect on all deliberate attempts that you have made to influence someone else's moods or emotions, and all attempts that you believe others have made to deliberately influence your own moods or emotions." As well as reporting the strategies used to regulate affect, participants were also prompted to note contextual information, for example, about the affective state regulated and the relationship within which the strategy was used. This approach allowed us to capture strategies that may have been used less frequently but could still be theoretically important.

From these three studies, participants reported a total of 955 strategy examples. To identify how many of these strategies were unique, we first rewrote each example as a statement that used the active voice in the present tense and made reference to the target, for example, "listening to the target's problems." Strategies that were highly similar were integrated into single strategies, and duplicate strategies were removed. The result was a final corpus of 378 distinct interpersonal affect regulation strategies.

\section{Stage II: Classifying the Interpersonal Affect Regulation Strategies}

To classify the strategies generated, a card-sort procedure was used, involving 20 participants ( 9 men and 11 women), aged between 21 and $61(M=36$ years, $S D=12.8)$, who were not trained in psychology. Participants were recruited through a variety of means including personal contacts and referrals. The sample size was informed by Tullis and Wood (2004), who found that the reliability of solutions from card-sort tasks does not substantially increase with sample sizes exceeding 20.

Participants were given separate cards with each of the 378 distinct strategies printed on them. We asked the participants to sort the strategies into mutually exclusive groups that reflected their own perceptions of similarities and differences. They were instructed to form as many or as few categories as they felt was appropriate, each containing as many or as few strategies as they wished. The task took participants an average of $2.5 \mathrm{hr}$ to complete. Some participants created just two categories, while others created more complex classifications involving up to 44 categories $(M=15, S D=11.3)$. There were no significant differences between the number of categories formed by males $(M=12)$ and females $(M=18), t(18)=1.17, n s$, and the number of categories formed was unrelated to age $(r=-.26, n s)$. Once participants had grouped the strategies, they named each grouping they had formed to help explain commonalities between the strategies contained within the grouping.

\section{Stage III: Analyzing the Interpersonal Affect Regulation Strategies}

There were two main phases to our analysis. The first phase was the construction of similarity matrices to test whether participants' judgments of similarities and differences during the card-sort task supported the distinctions proposed in the theoretical classification. The second phase was a hierarchical cluster analysis of the card-sort data to test whether the structure of the participants' consensual classification supported the categories proposed in the theoretical classification.

Constructing and analyzing the similarity matrices. To determine whether participants' judgments supported the proposed theoretical distinctions, we constructed a similarity matrix to represent the raw card sort data (referred to as the original similarity matrix). A $378 \times 378$ matrix was created for every participant, indicating whether each pair of strategies was placed in the same grouping ("1") or in a different grouping ("0") in the participant's card-sort solution. These matrices were then aggregated cell-bycell to create a matrix with cell values ranging between 0 (if no participants had placed a particular pair of strategies in the same group) and 20 (if all participants had placed the pair in the same group). We checked the internal consistency of this matrix by reaggregating and then correlating the original similarity matrices of odd- numbered participants and even-numbered participants (e.g., Romesburg, 1984). This produced a significant and large correlation $(r=.72, p<.01)$, suggesting a good level of consensus among participants regarding whether pairs of strategies were similar or different.

Two additional researchers familiar with the affect regulation literature then independently coded each of the 378 distinct strat- 
egies into the categories from our theoretical classification, and reached a consensus view on where the strategies should be allocated. This allocation was used to form a set of three $378 \times$ 378 similarity matrices, each of which represented one of the major distinctions proposed in the theoretical classification. The first matrix was based on our top-level distinction between strategies intended to improve and to worsen others' affect, the second matrix was based on our second-level distinction between cognitive and behavioral strategies, and the third matrix was based on our third-level distinction between engagement and diversion strategies. In each matrix, pairs of strategies were assigned a score of 1 if the researchers had allocated them in the same proposed category and a score of 0 if the strategies were allocated in different categories. We then correlated each cell from the original similarity matrix with the corresponding cell from each of the theoretically based matrices (e.g., Romesburg, 1984), to test whether the participants distinguished between the strategies using the distinctions proposed in our theoretical classification. Significant associations would provide support for the theoretical distinctions.

Hierarchical cluster analysis. To establish whether the underlying structure of the participants' classifications supported the theoretical classification, we subjected the original similarity matrix to hierarchical cluster analysis. Hierarchical cluster analysis organizes entities (in this case, strategies) into relatively homogeneous groups (Aldenderfer \& Blashfield, 1984), thus allowing us to identify the commonalities and distinctions that were salient to the participant group as a whole. An agglomerative clustering method was chosen, whereby the most similar strategies were sequentially merged to produce nonoverlapping hierarchically nested clusters of increasing inclusiveness. The average linkage rule (Sokal \& Michener, 1958), also referred to as the within-group linkage method, was used. This rule joins the two most similar cases together in a cluster, and then calculates the average similarity of a case with all other cases within and outside the cluster. A case only joins a cluster if a given level of overall similarity is achieved.

The main output from this clustering process is a dendrogram, which graphically represents how the 378 strategies group into hierarchically nested clusters. To reduce this complex representation to a more simplified and meaningful solution, we first visually inspected it, to determine the number of clusters at different levels of abstraction. We then interpreted the clusters produced at each level, using two main sources of information. The first source of information was a prototype analysis that identified which strategies were closest to the meaning of each cluster (Parkinson \& Totterdell, 1999; Shaver et al., 1987). The prototype analysis involved calculating the mean number of times that each member of a cluster was placed in the same grouping as each of the other cluster members. Those strategies that appeared with other members of the cluster the most times were considered most prototypical. The second source of information was the names participants gave to their groupings during the card-sort task.

Based on our interpretations of the clusters, we made a decision regarding the lowest meaningful level of abstraction to distinguish, by examining the clusters at the lowest level of abstraction and working upward. To be considered meaningful, a level of abstraction needed identifiable similarities between strategies in the same clusters and distinctions between strategies in different clusters.
Practical factors affecting the parsimony of the classification (e.g., the number of clusters produced at each level) were also considered. A simplified similarity matrix was constructed to represent the degree of similarity between pairs of strategies in this simplified solution ("0" for strategies that never appeared in the same category together, " 1 " for strategies that only appeared together in the same first-level category, "2" for strategies that appeared together in the same second-level category but no lower levels, and so on). This simplified matrix correlated strongly with the original similarity matrix $(r=.73, p<.01)$, suggesting that the simplified solution was an accurate but more parsimonious interpretation of the structure of the participants' consensual classification.

We then examined the degree of overlap between clusters from the simplified solution and the categories proposed in the theoretical classification. Here we examined the percentage of strategies appearing in analogous categories, to determine whether the proposed theoretical categories of controlled interpersonal affect regulation were supported.

\section{Results}

Correlations between the similarity matrix representing the raw card-sort data and the matrices representing categories from the theoretical framework provided partial support for the distinctions proposed in the theoretical classification. In particular, the original similarity matrix correlated strongly with the theoretical similarity matrix representing the categories of improving and worsening affect $(r=.66, p<.01)$. Given that the original similarity matrix took into account all distinctions made by participants, whereas the theoretical matrix only took into account a single distinction, the large size of this correlation (e.g., Cohen, 1988) suggests a good degree of support for this proposed distinction. Significant correlations were also found between the original similarity matrix and the theoretical matrices representing the categories of cognitive and behavioral strategies $(r=.11, p<.01)$ and engagement and diversion strategies $(r=.10, p<.01)$. However, the smaller size of these correlations indicates that these distinctions may have been less salient to participants when grouping the strategies.

Additional support for the categories proposed in the theoretical framework was sought by analyzing the underlying structure of the participants' consensual classification. The simplified solution to the participants' classification is displayed in Figures 1 and 2. The figures also list the most prototypical strategies from each lowestlevel cluster.

As can be seen from Figures 1 and 2, the participants' classification comprised three meaningful levels of abstraction, which we interpreted as: motive, primary means and secondary means. At the first level of abstraction, a distinction was made according to the motive behind interpersonal affect regulation: to improve the target's affect (affect improving) or to worsen the target's affect (affect worsening). This interpretation of the highest-level distinction was supported by the most prototypical strategies belonging to each cluster: "making time for the target" (affect improving) and "being unfriendly toward the target" (affect worsening). There was roughly the same number of strategies to improve (199) and to worsen (179) others' affect. This highest-level distinction supported that proposed in the theoretical classification. In fact, $98 \%$ of strategies that had been classified as affect-improving based on the theoretical framework appeared in the affect-improving cluster 


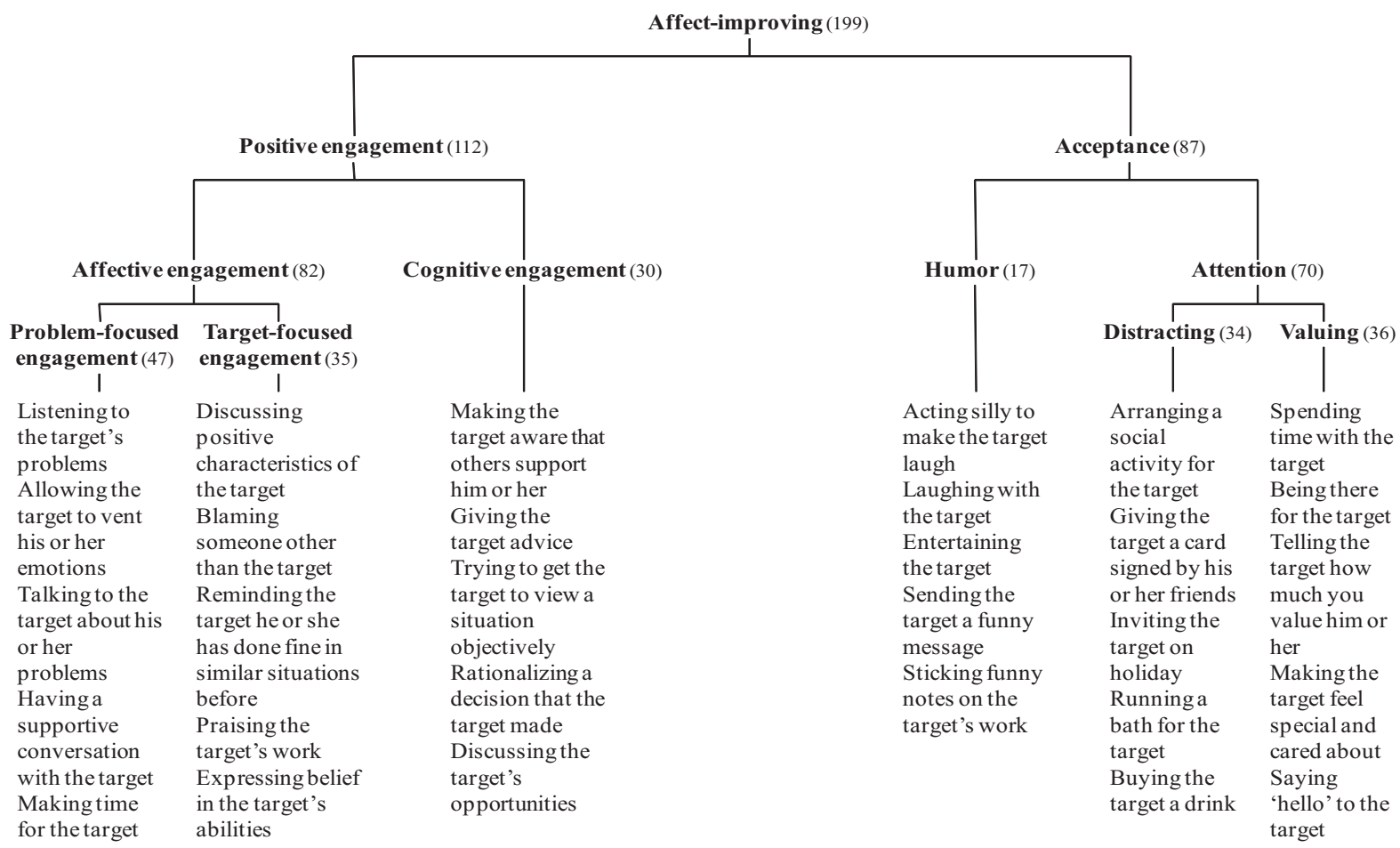

Figure 1. Hierarchical structure of the Strategies to Improve Affect cluster from the simplified participants' classification.

of the participants' classification, and $95 \%$ of strategies classed as affect-worsening based on the theoretical classification appeared in the affect-worsening cluster of the participants' classification.

At the second level of abstraction in the participants' classification, each of these clusters was split into two categories, on the basis of the primary means used to achieve interpersonal affect regulation. The primary means concerned whether the agent was strategically attempting to focus the target's attention on the target's situation or affective state or on the target's relationship with the agent. In the affect-improving cluster, the primary means categories were labeled positive engagement and acceptance. Positive engagement entails the agent attempting to involve the target

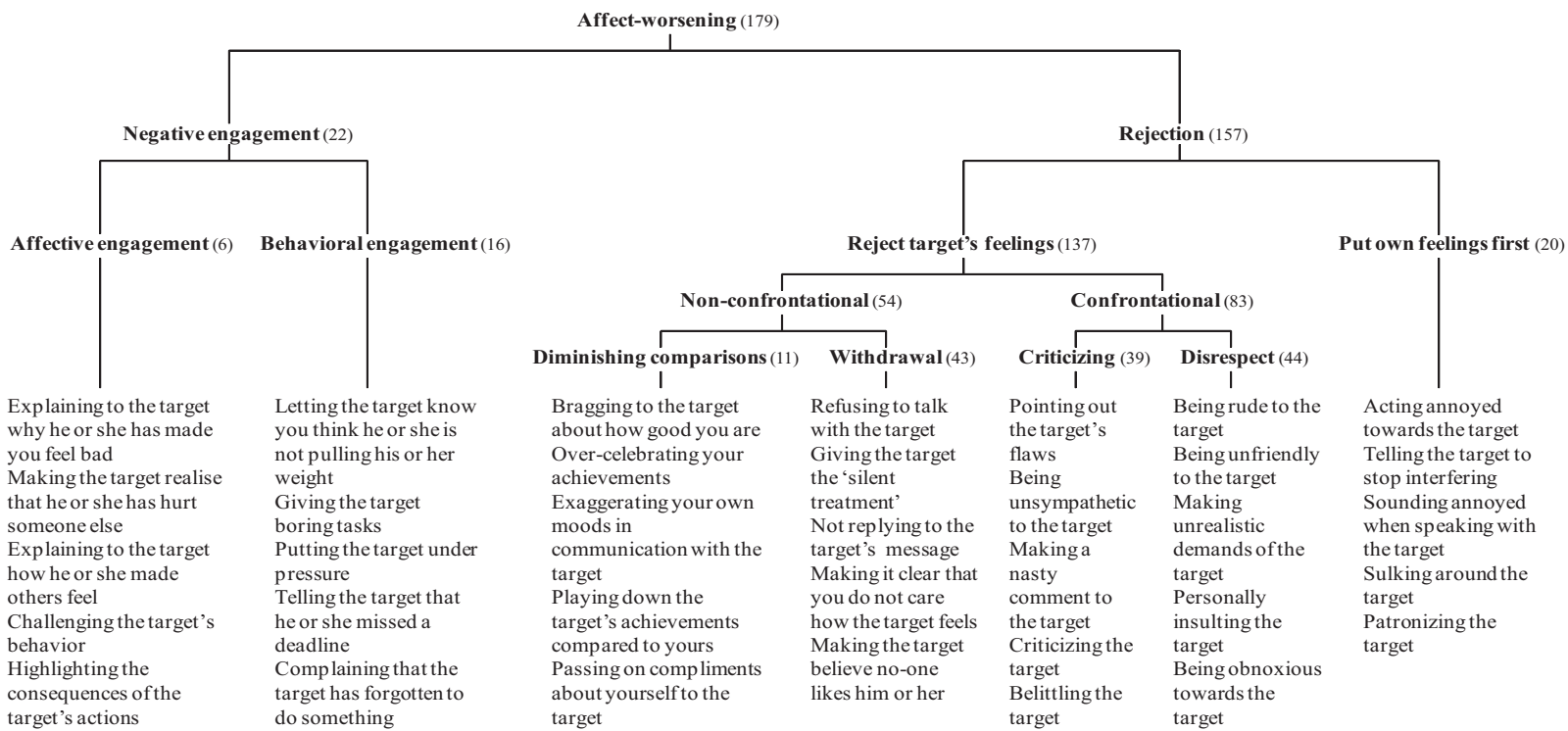

Figure 2. Hierarchical structure of the Strategies to Worsen Affect cluster from the simplified participants' classification. 
with his or her situation or affect in order to improve the target's affect (prototype strategy "talking to the target about his or her problems"), whereas acceptance involves behaviors that communicate validation of the target (prototype strategy "being friendly to the target"). In the affect-worsening cluster, the primary means categories were labeled negative engagement and rejection. Negative engagement entails the agent involving the target with a situation or affective state in order to worsen his or her affect (prototype strategy "expressing disappointment when the target has failed to reach a deadline"), while rejection involves behaviors that communicate snubbing of the target (prototype strategy "being obnoxious to the target"). Similar labels were also used by cardsort participants. For example, with respect to worsening affect, participants described categories of "prompting others to reconsider their actions" (Participant 1, male, 26 years old) and "rejection" (Participant 15, male, 57 years old). There were far fewer negative engagement strategies (22) compared with rejection strategies (157). In contrast, there were similar numbers of positive engagement (112) and acceptance strategies (87).

There was some obvious correspondence between these clusters and those proposed in the theoretical classification, because engagement categories appeared in both classifications. Indeed, the affect improving side of the participants' classification matched well to the theoretical classification, with $82 \%$ of the strategies classified as positive engagement based on the theoretical framework appearing in the positive engagement cluster of the participants' classification, and $85 \%$ of the strategies classed as positive diversion in the theoretical classification appearing in the acceptance cluster of the participants' classification. However, there was a major difference between the classifications with respect to the affect worsening strategies at this level of abstraction. While $92 \%$ of the strategies classified as negative diversion based on the theoretical framework appeared in the rejection cluster of the participants' classification, just $18 \%$ of the strategies classed as negative engagement in the theoretical classification appeared in the corresponding negative engagement cluster in the participants' classification. The majority of the strategies classified as negative engagement in the theoretical framework (78\%) appeared as rejection strategies in the participants' classification.

At the third level of abstraction in the participants' classification, each of the four clusters-positive engagement, acceptance, negative engagement and rejection-was further split into at least two clusters. These lower-level clusters represented secondary, more specific means used to achieve interpersonal affect regulation, which are detailed below.

\section{Positive Engagement}

Within the positive engagement category, a further distinction was made between two secondary categories. The first category, affective engagement, comprised strategies that engaged directly with the target's feelings (prototype strategy "allowing the target to vent his or her emotions"). Within this category, there was a further distinction according to whether the agent is focusing the target's attention on the situation (problem-focused engagement; prototype strategy "listening to the target's problems"), or on the target him- or herself (target-focused engagement; prototype strategy "discussing all the positive characteristics of the target"). The second category, cognitive engagement, was concerned with strat- egies that engaged with the target's cognitions in order to change his or her affect (prototype strategy "giving the target advice"). Similar category names were also suggested by participants, for example "emotionally based boost" (Participant 11, male, 25 years old) and "rationalizing" (Participant 12, female, 32 years old). The cognitive engagement cluster provided some support for the cognitive-behavioral distinction proposed in the theoretical classification, as strategies from the cognitive engagement cluster of the participants' classification largely came from the cognitive engagement category within the theoretical framework $(83 \%)$. However, there was no corresponding behavioral engagement cluster in the participants' classification; strategies from the affective engagement cluster came from both positive cognitive engagement $(48 \%)$ and positive behavioral engagement $(40 \%)$ categories in the theoretical framework.

\section{Acceptance}

Within the acceptance category, there were also two secondary categories. The first category comprised strategies that involved giving the target attention (prototype strategy "arranging a social activity involving the target"). A further distinction in the attention category was between distraction (prototype strategy "arranging a social activity involving the target") and valuing (prototype strategy "spending time with the target"). The second category comprised strategies that signaled acceptance using humor (prototype strategy "acting silly to make the target laugh"). Participants used similar category names within their individual card sorts, for example, "being attentive" (Participant 3, female, 24 years old) and "humor" (Participant 14, female, 39 years old). Although none of the clusters were labeled as cognitive or behavioral, strategies in the humor cluster the participants' classification were largely classed as cognitive in the theoretical framework (65\%), while strategies in the attention cluster were largely classed as behavioral $(74 \%)$.

\section{Negative Engagement}

Within the negative engagement category, a distinction was made between the secondary means of engaging directly with the target's feelings (affective engagement; prototype strategy "explaining to the target why they have made you feel bad") and engaging with the target's behavior in order to change his or her affect (behavioral engagement; prototype strategy "letting the target know you think they are not pulling their weight"). Almost all of the strategies in the negative engagement cluster of the participants' classification came from the negative cognitive engagement category from the theoretical framework $(82 \%)$.

\section{Rejection}

Within the rejection category, a further distinction was made between two secondary categories. The first category was "putting one's own feelings first," which typically took the form of displaying one's dissatisfaction to the target (prototype strategy "acting very annoyed toward the target"). One participant alluded to such a category as "being self-absorbed" (Participant 3, female, 24 years old). Most of the strategies in this cluster were classified as behavioral in the theoretical framework (70\%). 
The second category, "rejecting the target's feelings," concerned acting in a manner that displayed a lack of care for the target (prototype strategy "making it clear that you do not care how the target feels"). Within this category, a distinction emerged between strategies that signaled rejection using confrontational means versus strategies that used nonconfrontational means. Confrontational interpersonal affect regulation took one of two forms: criticizing (prototype strategy "pointing out the target's flaws") and disrespecting (prototype strategy "being rude to the target"). Participants used similar terms to describe such categories, including "personal criticism" (Participant 8, female, 30 years old) and "displaying a lack of respect" (Participant 2, male, 53 years old). Nonconfrontational interpersonal affect regulation also involved one of two means: diminishing comparisons (prototype strategy "bragging to the target about how good you are") and withdrawal (prototype strategy "refusing to talk with the target"). Again, participants used similar terms to describe their own groupings, for instance "put target down" (Participant 11, male, 25 years old) and "withdraw" (Participant 8, female, 30 years old). Here, slightly more of the confrontational strategies were classified as cognitive in the theoretical framework (54\%), while most of the nonconfrontational strategies were seen as behavioral $(70 \%)$.

\section{Discussion}

The aim of this research was to develop a conceptual classification of controlled interpersonal affect regulation strategies. We proposed a theoretical classification, based on Parkinson and Totterdell (1999), which distinguished between eight categories of interpersonal affect regulation strategies according to three factors. The first factor was the motive behind interpersonal affect regulation (affect-improving or affect-worsening), while the second and third factors related to the means used to achieve regulation (cognitive or behavioral and engagement or diversion, respectively). We tested this classification empirically using a card-sort of almost 400 distinct interpersonal affect regulation strategies with independent participants.

The simplified, parsimonious representation of the participants' classification provided good support for the highest-level distinction proposed in our theoretical classification, as participants also distinguished between affect-improving and affect-worsening strategies at the highest level of their consensual classification. Moreover, correlation analyses suggested that the theoretical distinction between affect-improving and affect-worsening accounted for a large amount of variance in participants' judgments of similarities and differences between controlled interpersonal affect regulation strategies. Because the distinction between affectimproving and affect-worsening strategies was considered to be fundamental, both theoretically and by the participants, we contend that it should remain at the highest level in the accepted classification.

In contrast, our analyses provided far less support for our proposed second-level distinction between cognitive and behavioral strategies. There was only a weak correlation between the participants' raw card-sort results and a theoretical similarity matrix representing this distinction. Furthermore, the clusters produced at the second level of abstraction in the participants' classification did not correspond with the proposed cognitive and behavioral categories, and none of the participants created groups relating to cognitive and behavioral strategies in their individual card-sort solutions. Despite some overlap between clusters produced at lower levels of the participants' consensual classification and the cognitive-behavioral distinction, clusters at these lower levels were not distinguished primarily on the basis of whether they were implemented cognitively versus behaviorally. Taken together, these findings suggest that the distinction between cognitive and behavioral strategies may be more salient to the regulation of one's own affect than the regulation of others' affect. Certainly, the researchers who classified the strategies into the theoretical framework reported difficulties in assigning many of the strategies to a cognitive or behavioral category. Based on the lack of support from the participants' classification, and the researchers' difficulties, we propose that this distinction should not be included in the accepted classification.

Rather than distinguishing between cognitive and behavioral strategies, at the second level of their classification participants instead distinguished strategies that focused the target on his or her situation or affective state (positive engagement and negative engagement) from those that focused the target on his or her relationship with the agent (acceptance and rejection). The clusters produced at this level of abstraction in the participants' classification shared commonalities with the engagement and diversion categories proposed at the third level of our theoretical classification. Both classifications distinguished engagement from nonengagement strategies, and although the nonengagement clusters of the participants' classification did not pertain to diversion per se, there was a high degree of overlap between strategies appearing in the acceptance cluster and the positive diversion category of the theoretical classification. However, there was a relatively weak statistical association between the raw card-sort results and the theoretical similarity matrix representing engagement-diversion. In addition, there were clear differences in how the negative categories from each classification system matched up.

These differences are likely to stem from the fact that the participants distinguished engagement strategies from strategies focusing on the relationship between agent and target as opposed to diversion strategies. Given the inherently social nature of interpersonal affect regulation, it does seem appropriate to recognize strategies that focus on the agent-target relationship. Indeed, engagement and relationship-oriented strategy types are consistent, respectively, with the broader social goals of achieving influence over the target's attitudes or behavior and strengthening or weakening social relationships, that controlled interpersonal affect regulation is often used to fulfill. Moreover, engagement and relationship-oriented strategies_-and the social goals they may be used to fulfill — can be linked to the circumplex model of interpersonal behavior (e.g., Wiggins, 1979). The circumplex model is organized around orthogonal dimensions of agentic behaviors (used to signal dominance or submissiveness), which overlap conceptually with engagement strategies and the goal of interpersonal influence; and communal behaviors (used to signal friendliness or hostility), which share links with relationship-oriented strategies and the goals of strengthening or weakening relationships. Additional testimony to the relevance of this distinction can be found within the wider communications literature, in which a distinction is commonly made between instrumental and relational forms of communication (e.g., Fitzpatrick \& Indvik, 1982; Taylor, 2002). Engagement is analogous to instrumental communication, 
because both are focused on the task or situation. Relationshiporiented strategies are comparable to relational forms of communication, where the social tie between the agent and target is central to the meaning and significance of behavior.

Thus, the distinction between engagement and relationshiporiented strategies is supported by relevant theories, and had parallels with our theoretical classification. These factors, along with the salience attributed to this distinction in the participants' classification, lead us to propose that the distinction between engagement and relationship-oriented strategies should be made at the second level of the accepted classification.

Although we had proposed three hierarchically nested distinctions in our theoretical classification, the participants' classification included many additional lower-level clusters that represented different means of achieving interpersonal affect regulation. While we had not predicted these clusters, many of these means are included in classifications of relevant interpersonal processes or have been discussed in studies of interpersonal affect regulation (see Table 1). Thus, almost all clusters at the lower levels of the participants' classification correspond to previous research. The placement of particular means of regulation within higher-order clusters is likely to be based on the perceived social function of strategy types. For instance, while humor could be used to engage the target in a situation (e.g., to make light of a problem), for the participants it was seen to function primarily to signal acceptance of the target.

Another notable feature of the participants' classification that we had not anticipated was the asymmetrical spread of strategies in the classification. In particular, there were far-fewer strategies classified as engagement compared with relationship-oriented in the affect-worsening cluster, whereas there was a more even spread between these categories in the affect-improving cluster. It could be that more variations of a strategy type will be developed if there is more opportunity and requirement for their use. The richer variety of negative relationship-oriented strategies might therefore result from a greater demand for strategies to serve the function of rejecting as opposed to engaging the target when trying to worsen someone else's affect.

Our revised proposal for a classification of controlled interpersonal affect regulation strategies is shown in Table 3. This final classification is based on the theoretical distinctions between strategy types we originally proposed, with relabeling, omissions and additions made on the basis of the results of the card-sort task. The classification makes two main distinctions between types of controlled interpersonal affect regulation strategies. The first distinction is between affect-improving and affect-worsening strategies, and the second is between engagement and relationship-oriented strategies. Within each of the four main strategy types that result from these distinctions, more specific means of achieving interpersonal affect regulation are distinguished. The high internal consistency within the participants' card-sort data, and the parallels between distinctions made in the participants' classification and extant theory and research, support this classification.

The present research has a number of limitations. First, the large number of strategies involved in the research may have compromised the classification process. Grouping almost 400 strategies required individuals to keep in mind a great deal of information. The relatively undifferentiated classification systems generated by a few participants may therefore have been produced under the constraint of cognitive load. Nevertheless, including all distinct strategies generated in the research was necessary to create a comprehensive classification that represented all possible conceptually important distinctions. Now that the highest-level distinction between affect improving and affect worsening has been established, further research can attempt to classify strategies within these clusters separately, to reduce the load on participants.

A second limitation is the use of self-report techniques to generate the interpersonal affect regulation strategies. This may have resulted in some theoretically important strategies being omitted because they tend to be used habitually, without conscious

Table 3

Final Classification of Controlled Interpersonal Affect Regulation Strategies

\begin{tabular}{|c|c|c|}
\hline & Strategies to improve affect & Strategies to worsen affect \\
\hline \multirow{5}{*}{$\begin{array}{l}\text { Engagement } \\
\text { strategies }\end{array}$} & Positive engagement & Negative engagement \\
\hline & $\begin{array}{l}\text { Affective engagement: Directly trying to improve the way } \\
\text { the target feels about a situation, e.g., allowing the } \\
\text { target to vent }\end{array}$ & $\begin{array}{l}\text { Affective engagement: Directly trying to worsen the way the } \\
\text { target feels about a situation, e.g., explaining how the } \\
\text { target has hurt someone }\end{array}$ \\
\hline & $\begin{array}{l}\text { Problem-focused strategies, e.g., listening to the target's } \\
\text { problems }\end{array}$ & \\
\hline & $\begin{array}{l}\text { Target-focused strategies, e.g., pointing out the target's } \\
\text { positive characteristics }\end{array}$ & \\
\hline & $\begin{array}{l}\text { Cognitive engagement: Trying to change the way the target } \\
\text { thinks about a situation in order to improve the } \\
\text { target's feelings, e.g., giving the target advice }\end{array}$ & $\begin{array}{l}\text { Behavioral engagement: Trying to change the way the target } \\
\text { behaves in relation to a situation in order to worsen the } \\
\text { target's feelings, e.g., complaining about the target's } \\
\text { behavior }\end{array}$ \\
\hline \multirow{5}{*}{$\begin{array}{l}\text { Relationship-oriented } \\
\text { strategies }\end{array}$} & Acceptance & Rejection \\
\hline & $\begin{array}{l}\text { Attention: Giving the target attention to communicate } \\
\text { validation, e.g., making it clear that you care about the } \\
\text { target }\end{array}$ & $\begin{array}{l}\text { Rejecting the target's feelings: Rejecting the target's } \\
\text { feelings to communicate snubbing, e.g., making it clear } \\
\text { that you do not care how the target feels }\end{array}$ \\
\hline & Valuing, e.g., making the target feel special & Confrontational strategies, e.g., being rude to the target \\
\hline & Distraction, e.g., arranging an activity for the target & Nonconfrontational strategies, e.g., ignoring the target \\
\hline & $\begin{array}{l}\text { Humor: Being humorous towards the target to } \\
\text { communicate validation, e.g., joking with the target }\end{array}$ & $\begin{array}{l}\text { Putting one's own feelings first: Putting one's own feelings } \\
\text { first to communicate snubbing, e.g., sulking around the } \\
\text { target }\end{array}$ \\
\hline
\end{tabular}


awareness. Indeed, the relatively low numbers of negative engagement strategies in the final classification could have resulted from people being unaware of using such behaviors. However, we took steps to overcome this potential problem by asking participants to report acts of controlled interpersonal affect regulation enacted toward them or that they had witnessed as well as acts they had performed. The fact that our strategy generation methods produced strategies that fit into each of the eight theoretically based categories we proposed also lends support to our approach.

A third limitation regards the applicability of the classification to specific contexts and permutations of interpersonal affect regulation. Our aim in developing this classification was to provide a generalized way of organizing strategies used to regulate others' experienced affect, so our card-sort participants were not given any contextual cues when they grouped the strategies. Further research is necessary to determine whether the same types of strategies are used to regulate the way that others express their emotions and moods, and whether the distinctions made in the classification apply to all permutations of interpersonal affect regulation in all contexts. It may be that certain strategy types are favored in particular circumstances but that the distinctions we propose are robust.

The classification produced from this research shows the underlying communalities of controlled interpersonal affect regulation strategies. To date, there have been a number of studies exploring controlled interpersonal affect regulation, and the process has also been subsumed into several disparate research areas (e.g., interpersonal influence, emotional labor). These bodies of literature have previously not been comparable because of the lack of common framework. Our classification provides an integrative framework with which to organize and understand existing studies of interpersonal affect regulation and like processes. For instance, the classification can be used alongside the circumplex model of interpersonal behavior (e.g., Wiggins, 1979) to make inferences about the strategies used to regulate others' affect in particular relationships or by particular people. Engagement strategies may be used to regulate affect in agentic relationships, or by those who have an inclination toward dominance behaviors. Relationshiporiented strategies may be preferred in communal relationships, or by those with an inclination toward affiliation or hostility behaviors.

In addition, our final classification offers a useful basis for organizing future research regarding interpersonal affect regulation. This research area is still emerging and hence the classification could be used to help advance and refine the conceptualization and measurement of controlled interpersonal affect regulation, and to address important, unanswered research questions. For instance, which strategies are most effective for improving or worsening others' affect? Are there social and health consequences of enacting and receiving interpersonal affect regulation strategies? The current classification offers a sound basis for comparing the effects of different types of interpersonal affect regulation. The classification could also extend current avenues of investigation regarding emotion roles (e.g., What strategy types are used by people who occupy different roles?) and the ability to regulate others' affect (e.g., Are individuals with high regulatory ability more skilled at using particular strategy types?).

The grounding of our classification in people's everyday understanding of interpersonal affect regulation promises that people will be able to recognize and differentiate, and potentially alter, their own and others' use of the interpersonal affect regulation strategies identified in this research. We believe that the current classification provides a good starting point for understanding the ways in which people deliberately attempt to influence and change other people's affect, and a meaningful basis for making comparisons between different types of controlled interpersonal affect regulation strategies.

\section{References}

Aldenderfer, M. S., \& Blashfield, R. K. (1984). Cluster analysis. Newbury Park, CA: Sage.

Buss, D. M. (1992). Manipulation in close relationships: Five personality factors in interactional context. Journal of Personality, 60, 477-499.

Buss, D. M., Gomes, M., Higgins, D. S., \& Lauterbach, K. (1987). Tactics of manipulation. Journal of Personality and Social Psychology, 52, 1219-1229.

Cahill, S. E., \& Eggleston, R. (1994). Managing emotions in public: The case of wheelchair users. Social Psychology Quarterly, 57, 300-312.

Cohen, J. (1988). Statistical power analysis for the behavioral sciences (2nd ed.). Hillsdale, NJ: Erlbaum.

Crawley, E. M. (2004). Emotion and performance: Prison officers and the presentation of staff in prisons. Punishment and Society, 6, 411-427.

Cross, R., Baker, W., \& Parker, A. (2003). What creates energy in organizations? Sloan Management Review, 44, 51-57.

Eisenberg, N., Fabes, R. A., Guthrie, I. K., \& Reiser, M. (2000). Dispositional emotionality and regulation: Their role in predicting quality of social functioning. Journal of Personality and Social Psychology, 78, $136-157$.

Field, T. (1994). The effects of mothers' physical and emotional unavailability on emotion regulation. Monographs of the Society for Research in Child Development, 59, 208-227.

Fitzpatrick, M. A., \& Indvik, J. (1982). The instrumental and expressive domains of marital communication. Human Communication Research, 8, 195-213.

Francis, L. E., Monahan, K., \& Berger, C. (1999). A laughing matter? The uses of humor in medical interactions. Motivation and Emotion, 23, $154-177$.

Frost, P. J., \& Robinson, S. (1999). The toxic handler: Organizational hero and casualty. Harvard Business Review, 77, 96-106.

Gianino, A., \& Tronick, E. Z. (1988). The mutual regulation model: The infant's self and interactive regulation and coping defense capacities. In T. Field, P. McCabe, \& N. Schneiderman (Eds.), Stress and coping across development (pp. 47-68). Hillsdale, NJ: Erlbaum.

Goffman, E. (1955). On face-work: An analysis of ritual elements in social interaction. Psychiatry, 18, 213-231.

Gross, J. J. (1998). Antecedent- and response-focused emotion regulation: Divergent consequences for experience, expression, and physiology. Journal of Personality and Social Psychology, 74, 224-237.

Gross, J. J. (1999). Emotion regulation: Past, present, future. Cognition and Emotion, 13, 551-573.

Gross, J. J., \& Thompson, R. A. (2007). Emotion regulation: Conceptual foundations. In J. J. Gross (Ed.), Handbook of emotion regulation (pp. 3-26). New York: Guilford Press.

Henderson, M., \& Argyle, M. (1985). Social support by four categories of work colleagues: Relationships between activities, stress and satisfaction. Journal of Occupational Behavior, 6, 229-239.

House, J. S., \& Kahn, R. L. (1985). Measures and concepts of social support. In S. Cohen \& S. L. Syme (Eds.), Social support and health (pp. 79-108). Orlando, FL: Academic Press.

Jones, E. E., \& Pittman, T. S. (1982). Toward a general theory of strategic self-presentation. In J. Suls (Ed.), Psychological perspectives on the self (pp. 231-262). Hillsdale, NJ: Erlbaum. 
Kahn, W. A. (1993). Caring for the caregivers: Patterns of organizational caregiving. Administrative Science Quarterly, 38, 539-563.

Kipnis, D., Schmidt, S. M., \& Wilkinson, I. (1980). Intraorganizational influence tactics: Exploration of getting one's way. Journal of Applied Psychology, 65, 440-452.

Lively, K. J. (2000). Reciprocal emotion management: Working together to maintain stratification in private law firms. Work and Occupations, 27, $32-63$.

Locke, K. (1996). A funny thing happened: The management of consumer emotions in service encounters. Organization Science, 7, 40-59.

Neuman, J. H., \& Baron, R. A. (1998). Workplace violence and workplace aggression: Evidence concerning specific forms, potential causes, and preferred targets. Journal of Management, 24, 391-419.

Parkinson, B., Fischer, A. H., \& Manstead, A. S. R. (2005). Emotion in social relations: Cultural, group, and interpersonal processes. New York: Psychology Press.

Parkinson, B., \& Totterdell, P. (1999). Classifying affect regulation strategies. Cognition and Emotion, 13, 277-303.

Parkinson, B., Totterdell, P., Briner, R. B., \& Reynolds, S. (1996). Changing moods: The psychology of mood and mood regulation. Harlow, United Kingdom: Longman.

Parrott, W. G. (1993). Beyond hedonism: Motives for inhibiting good moods and for maintaining bad moods. In W. A. Pennebaker (Ed.), Handbook of mental control (pp. 279-305). Englewood Cliffs, NJ: Prentice Hall.

Pierce, J. L. (1999). Emotional labor among paralegals. Annals of the American Academy of Political and Social Science, 561, 127-142.

Rafaeli, A., \& Sutton, R. I. (1990). Busy stores and demanding customers: How do they affect the display of positive emotion? Academy of Management Journal, 33, 623-637.

Rafaeli, A., \& Sutton, R. I. (1991). Emotional contrast strategies as means of social influence: Lessons from criminal interrogators and bill collectors. Academy of Management Journal, 34, 749-775.

Romesburg, H. C. (1984). Cluster analysis for researchers. Belmont, CA: Lifetime Learning Publications.

Scheier, M. F., \& Carver, C. S. (1988). A model of behavioral selfregulation: Translating intention into action. Advances in Experimental Social Psychology, 21, 303-346.

Schrock, D., Holden, D., \& Reid, L. (2004). Creating emotional resonance: Interpersonal emotion work and motivational framing in a transgender community. Social Problems, 51, 61-81.

Shaver, P., Schwartz, J., Kirson, D., \& O'Connor, C. (1987). Emotion knowledge: Further exploration of a prototype approach. Journal of Personality and Social Psychology, 52, 1061-1086.

Shiffrin, R. M., \& Schneider, W. (1977). Controlled and automatic human information processing: Perceptual learning, automatic attending and a general theory. Psychological Review, 84, 127-190.

Sokal, R. R., \& Michener, C. D. (1958). A statistical method for evaluating systematic relationships. University of Kansas Scientific Bulletin, 38, $1409-1438$.

Sutton, R. I. (1991). Maintaining norms about expressed emotions: The case of bill collectors. Administrative Science Quarterly, 36, 245-268.

Taylor, P. J. (2002). A cylindrical model of communication behavior in crisis negotiations. Human Communication Research, 28, 7-48.

Thayer, R. E., Newman, R., \& McClain, T. M. (1994). Self-regulation of mood: Strategies for changing a bad mood, raising energy, and reducing tension. Journal of Personality and Social Psychology, 67, 910-925.

Thoits, P. A. (1996). Managing the emotions of others. Symbolic Interaction, 19, 85-109.

Thompson, R. A., \& Meyer, S. (2007). Socialization of emotion regulation in the family. In J. J. Gross (Ed.), Handbook of emotion regulation (pp. 249-268). New York: Guilford Press.

Totterdell, P., \& Holman, D. (2003). Emotional regulation in customer service roles: Testing a model of emotional labor. Journal of Occupational Health Psychology, 8, 55-73.

Totterdell, P., Kellett, S., Teuchmann, K., \& Briner, R. B. (1998). Evidence of mood linkage in work groups. Journal of Personality and Social Psychology, 74, 1504-1515.

Tullis, T., \& Wood, L. (2004). How many users are enough for a cardsorting study? In Proceedings University Press of America 2004, Minneapolis, June 7-11, 2004.

Vangelisti, A. L., Daly, J. A., \& Rudnick, J. R. (1991). Making people feel guilty in conversations: Techniques and correlates. Human Communication Research, 18, 3-39.

Waddington, K. (2005). Using diaries to explore the characteristics of work-related gossip: Methodological considerations from exploratory multimethod research. Journal of Occupational and Organizational Psychology, 78, 221-236.

Watson, D., \& Tellegen, A. (1985). Toward a consensual structure of mood. Psychological Bulletin, 98, 219-235.

Westen, D. (1994). Towards an integrative model of affect regulation: Applications to social-psychological research. Journal of Personality, 62, 641-667.

Wiggins, J. S. (1979). A psychological taxonomy of trait-descriptive terms: The interpersonal domain. Journal of Personality and Social Psychology, 33, 409-420.

Received October 14, 2008

Revision received March 17, 2009

Accepted March 19, 2009

\section{Correction to Said, Sebe, and Todorov (2009)}

In the article, "Structural Resemblance To Emotional Expressions Predicts Evaluation of Emotionally Neutral Faces" by Christopher Said, Nicu Sebe, and Alexander Todorov (Emotion, 2009, Vol. 9, No. 2, pp. 260-264) a symbol was incorrectly omitted from Figure 1, part C. To see the complete article with the corrected figure, please go to http://dx.doi.org/10.1037/a0014681 